\title{
Optical studies on sol-gel derived titanium dioxide films
}

\author{
A.K.Ray, S.M.Tracey, B.McQuillin and S.N.B.Hodgson
}

\begin{abstract}
Optical absorption $A(\lambda)$ and transmission $T(\lambda)$ spectra for normal incidence have been obtained within the wavelength $(\lambda)$ range $300-900 \mathrm{~nm}$ for titanium dioxide $\left(\mathrm{TiO}_{2}\right)$ films in anatase form prepared by the sol-gel method. The dispersion relation for refractive indices is in agreement with the oscillator model. The refractive index is found to be independent of thickness. Above the absorption tail, optical absorption is believed to be due to nondirect electronic processes involving no transitions between localised states in a single layer thick $\mathrm{TiO}_{2}$ film. For a multilayered film, transitions between localised states are probable as equal as those between all other states.
\end{abstract}

\section{Introduction}

Titanium dioxide $\left(\mathrm{TiO}_{2}\right)$ exhibits a range of potentially useful properties such as high refractive index, high dielectric constant and chemical stability. The material exists in three stable crystalline phases: brookite, anatase and rutile. Rutile is known to be the most stable phase. Due to practical importance the materials have attracted much interest in recent years for use in a variety of optical, electrical and optoelectronic applications including antireflectance coatings [1], electrochromic display devices [2] and planar waveguides [3, 4]. The materials can be formulated in thin film form by using sputtering [5], a plasma beam generator [6], chemical vapour deposition [7] and spin coating [8]. $\mathrm{TiO}_{2}$ thin films can also be prepared in amorphous form, with the anatase form being of particular interest for the rapidly developing areas of electrochemical and solid-state dye sensitised photovoltaic cells $[9,10]$. The polycrystalline and amorphous forms of $\mathrm{TiO}_{2}$ can be readily prepared using the sol-gel technique [11] which offers the possibility of relatively low cost, large-scale production of thin films. Recent work has identified significant interactions between process parameters such as withdrawal rate, sol concentration and the number of coating layers and their effects on structural, optical and electrical properties of sol-gel derived $\mathrm{TiO}_{2}$ films [12]. This article reports the results of optical measurements on sol-gel derived anatase films on glass substrates. Experimental data were analysed to determine the film thickness and refractive indices and to provide an interpretation of the electronic transition processes involved in optical absorption. The nature of interband transitions was not investigated in earlier studies and the present investigations now show that nondirect transitions are responsible for optical absorption. An electronic band structure is proposed for a polycrystalline $\mathrm{TiO}_{2}$ film. Sol-

\section{(C) IEE, 2000}

IEE Proceedings online no. 20000698

DOI: 10.1049/ip-smt:20000698

Paper first received 8th October 1999 and in revised form 2000

A.K. Ray, S.M. Tracey and B. McQuillin are with the Physical Electronics \& Fibre Optics Research Laboratories, School of Engineering, Sheffield Hallam University, Pond Street, Sheffield S1 1WB, UK

S.N.B. Hodgson is with the Institute of Polymer Technology and Materials Engineering, Loughborough University, Loughborough, Leicestershire LE11 3TU UK gel derived $\mathrm{TiO}_{2}$ films are normally used in dye-sensitised photoconductive cells $[13,14]$ and the knowledge of band properties is important for understanding the mechanism of charge transfer from the dye molecule to the oxide film.

\section{Experimental techniques}

Chemically and thermally stable films of titanium dioxide were prepared using the sol-gel method. A solution was prepared by mixing $5.04 \mathrm{ml}$ glacial acetic acid $\mathrm{CH}_{3} \mathrm{COOH}$ (Aldrich 99.5\%) and $50 \mathrm{ml}$ anhydrous ethanol (Aldrich $99.7-100 \%$ ) for $5 \mathrm{~min}$ and then $6.3 \mathrm{ml}$ titanium (IV) isopropoxide $\mathrm{Ti}\left[\mathrm{OCH}\left(\mathrm{CH}_{3}\right)_{2}\right]_{4}(97 \%$ pure $)$ was added to this solution. An additional period of $2 \mathrm{~min}$ was allowed for proper blending and dip coating was then carried out onto ultrasonically cleaned glass substrate under atmospheric conditions. The addition of acetic acid is necessary as a reactionmodifying agent to prevent the rapid and uncontrolled hydrolysis of the titanium alkoxide which otherwise forms particulate reaction products rather than gels suitable for dip coating. During the dipping process, the substrates were generally withdrawn with a speed of $250 \mathrm{~mm} / \mathrm{min}$ but different speeds were also used for comparative studies. The samples were allowed to dry in air for $24 \mathrm{~h}$ and subsequently heat treated at a temperature of $500^{\circ} \mathrm{C}$ for $5 \mathrm{~h}$. Heat treatment at temperatures higher than $500^{\circ} \mathrm{C}$ was not investigated due to the limitations of the glass substrates used. Using a Phillips PW 1710 diffractometer with monochromatic $\mathrm{Cu}$ radiation and a scan speed of 0.01 degree $(2 \theta)$ per second, X-ray diffraction studies were performed on residues of the sol mixture, which had been previously dried and then subjected to the same heat treatment as for the dip-coated films. Optical transmission and absorption spectra for the heat-treated $\mathrm{TiO}_{2}$ films were investigated using an ATI Unicam UV/visible spectrophotometer. The thickness of the films was also independently measured using a planar surfometer (Surfcom 300) with a stated accuracy of $\pm 0.01 \mu \mathrm{m}$. The stylus was made to traverse across the substrate up to the coating edge and beyond for a total distance of $2 \mathrm{~mm}$. For the purpose of electrical measurements, the $\mathrm{TiO}_{2}$ film was dip-coated on an $\mathrm{InSnO}_{2}$ substrate and gold was evaporated as a top electrode. All experiments were repeated and good reproducibility of the results was achieved. 


\section{Results and discussions}

Fig. 1 shows a typical powder X-ray diffraction pattern obtained from sol residues heated at $500^{\circ} \mathrm{C}$ for $5 \mathrm{~h}$. Using Bragg's law, values of interplanar spacing distance for each peak were calculated. The results of calculations are summarised in Table 1 and they correspond well to data for anatase $\mathrm{TiO}_{2}$ film. The rutile and brookite forms of $\mathrm{TiO}_{2}$ were not observed during these investigations. The amorphous phase of $\mathrm{TiO}_{2}$ film was obtained from the sols that were not affected by heat treatment. For comparison, the analysis of diffraction patterns for films manufactured under identical conditions, but heated to $350^{\circ} \mathrm{C}$ for the same length of time, does not produce similar results. The pattern in Fig. $1 b$ shows the form of $\mathrm{TiO}_{2}$ film to be predominantly amorphous with the appearance of two peaks corresponding to interplanar distances of $35.37 \mathrm{~nm}$ and $30.86 \mathrm{~nm}$ at angles of $\approx 25^{\circ}$ and $\approx 27^{\circ}$. It is therefore believed that the heat treatment temperature at $500^{\circ} \mathrm{C}$ caused a gradual crystallisation of the material to the anatase structure.
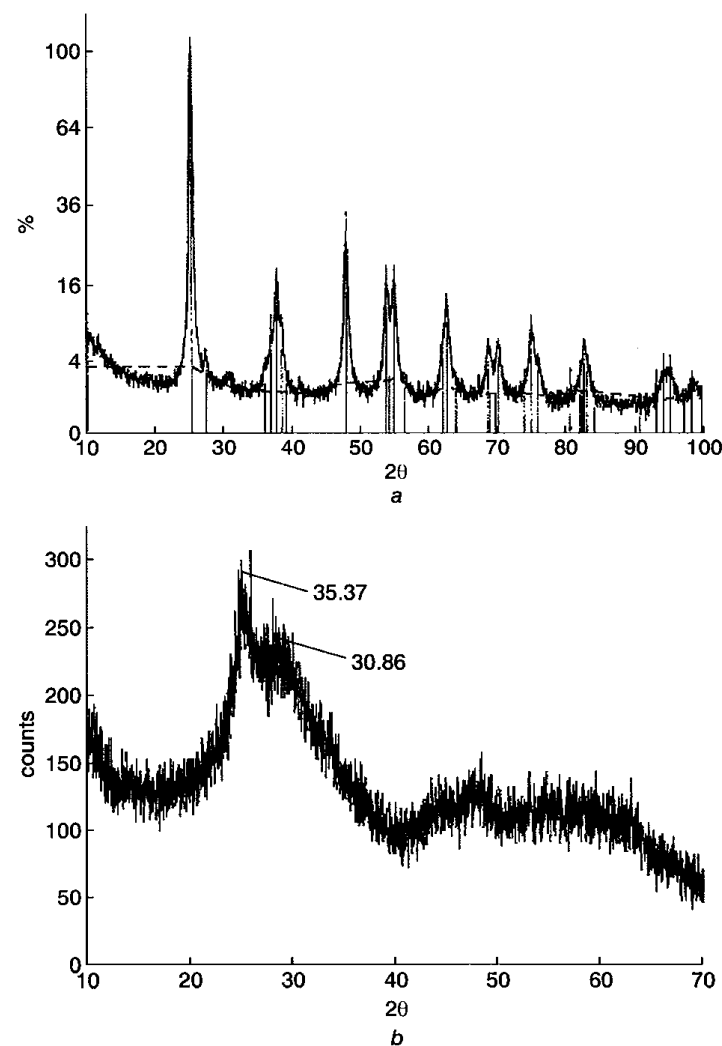

Fig. 1 Effect of heat treatment on the X-ray diffraction patterns of $\mathrm{TiO}_{2}$ solgel residues for a gel heated to $500^{\circ} \mathrm{C}$ and $350^{\circ} \mathrm{C}$ $a 500^{\circ} \mathrm{C}$
$b 350^{\circ} \mathrm{C}$

Fig. 2 shows typical transmission spectra for the bare glass substrate and also substrates coated with three different layers of $\mathrm{TiO}_{2}$ films. The spectra were corrected for the effects of optical absorption in the substrates. As expected, films exhibit a significantly large fraction of transmission for the range of wavelengths $350 \mathrm{~nm} \leq \lambda \leq 900 \mathrm{~nm}$. The appearance of interference fringes in the transmission spectra is caused by multiple reflections at the boundary of the film and the substrate. The number of maxima and minima in interference patterns increases with that of the layers. Interference patterns were found to disappear for samples coated with less than four layers. Using the condition for interference for two adjacent maxima (or minima) at wavelengths $\lambda_{1}$ and $\lambda_{2}$, the thickness $d$ of the $\mathrm{TiO}_{2}$ films is determined from the standard expression

$$
d=\frac{\lambda_{1} \lambda_{2}}{2\left[\lambda_{1} \mu\left(\lambda_{2}\right)-\lambda_{2} \mu\left(\lambda_{1}\right)\right]}
$$

where $\mu\left(\lambda_{1}\right)$ and $\mu\left(\lambda_{2}\right)$ are the refractive indices of the $\mathrm{TiO}_{2}$ film for $\lambda_{1}$ and $\lambda_{2}$, respectively.

Table 1: Measured values (a) and reference data (b) obtained for an anatase film from Philips PC-APD software for interplanar spacing

\begin{tabular}{|c|c|c|c|c|}
\hline \multirow{2}{*}{$\begin{array}{l}\text { Peak } \\
\text { number }\end{array}$} & \multicolumn{2}{|c|}{$\begin{array}{l}\text { Angle }\left({ }^{\circ}\right) \text { at which the } \\
\text { peak is positioned }\end{array}$} & \multicolumn{2}{|c|}{$\begin{array}{l}\text { Values of interplanar } \\
\text { spacing, } \mathrm{nm}\end{array}$} \\
\hline & (a) & $(b)$ & (a) & (b) \\
\hline 1 & 25.38 & 25.281 & 35.065 & 35.2 \\
\hline 2 & 37.78 & 37.801 & 23.793 & 23.78 \\
\hline 3 & 48.03 & 48.05 & 18.927 & 18.92 \\
\hline 4 & 53.83 & 53.891 & 17.017 & 16.999 \\
\hline 5 & 55.215 & 55.062 & 16.622 & 16.665 \\
\hline 6 & 62.79 & 62.69 & 14.787 & 14.808 \\
\hline 7 & 68.725 & 68.762 & 13.647 & 13.641 \\
\hline 8 & 70.255 & 70.311 & 13.387 & 13.378 \\
\hline 9 & 75.075 & 75.032 & 12.643 & 12.649 \\
\hline 10 & 82.7 & 82.662 & 11.66 & 11.664 \\
\hline
\end{tabular}

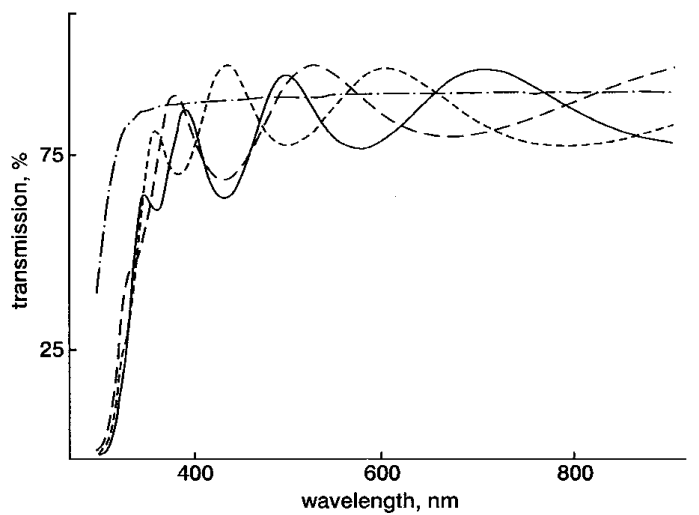

Fig.2 Transmission interference fringes observed for five-, six- and sevenlayer thick $\mathrm{TiO}_{2}$ films

Transmission spectrum $T_{S}$ for the glass substrate is also shown, withdrawal rate of $250 \mathrm{~mm} / \mathrm{min}$

--- five layers

- . - - six layers

$--T_{s}$

The method due to Swanepoel is employed to estimate the refractive indices $\mu(\lambda)$ [15]. If $\mu_{s}(\lambda)$ is the refractive index of the substrate, $\mu(\lambda)$ for the film can be found according to the formula

$$
\mu(\lambda)=\left[M+\sqrt{\left(M^{2}-\mu_{s}^{2}\right)}\right]^{1 / 2}
$$

where $M$ is given for a wavelength $\lambda$ in the form

$$
M=\frac{\mu_{s}^{2}+1}{2}+2 \mu_{s} \frac{T_{\max }(\lambda)-T_{\min }(\lambda)}{T_{\max }(\lambda) T_{\min }(\lambda)}
$$

$T_{\max }(\lambda)$ and $T_{\min }(\lambda)$ lie on the two curves enveloping the maxima and minima of the interference patterns. The refractive index $\mu_{s}(\lambda)$ is calculated from the transmission spectrum $T_{s}(\lambda)$ for the glass substrate using the expression of

IEE Proc.-Sci. Meas. Technol, Vol. 147, No. 6, November 2000 


$$
\mu_{s}(\lambda)=\frac{1}{T_{s}}+\sqrt{\frac{1}{T_{s}^{2}}-1}
$$

A selfconsistent iterative procedure was developed to solve eqns. $1-4$. The refractive index profile $\mu(\lambda)$ within the transmission regime and the thickness of the $\mathrm{TiO}_{2}$ film were calculated from the solutions. Parabolic interpolation between the three nearest experimental points is adopted to determine intermediate values of $T_{\max }(\lambda)$ and $T_{\min }(\lambda)$. Similar experiments were also carried out on films produced with a withdrawal rate of $100 \mathrm{~mm} / \mathrm{min}$.

Fig. 3 shows an approximately linear correlation between the number of applications and the overall coating thickness for both withdrawal rates of $250 \mathrm{~mm} / \mathrm{min}$ and $100 \mathrm{~mm} / \mathrm{min}$. As expected, films produced by a fast withdrawal rate are found to be thicker than those produced by a slow rate. Results obtained from the surface profile experiments show a reasonable degree of consistency between the two sets of data obtained from independent measurements.

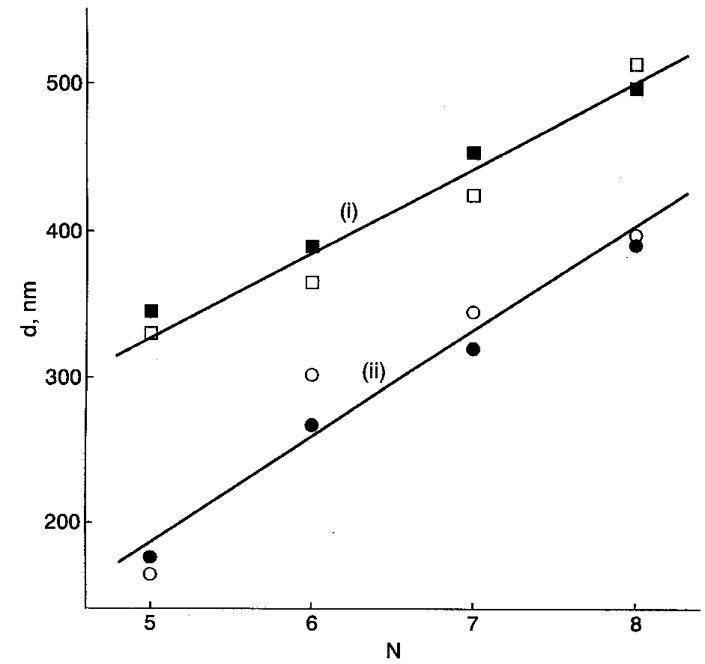

Fig.3 Set of two linear graphs showing the relationship between the thickness of $\mathrm{TiO}_{2}$ film and the mmber of applications for withdrawal rate of (i) $250 \mathrm{~mm}$ min and (ii) $100 \mathrm{~mm} / \mathrm{min}$

Open and closed symbols identify the data obtained from the Swanepoel method and the surface profiling measurements, respectively

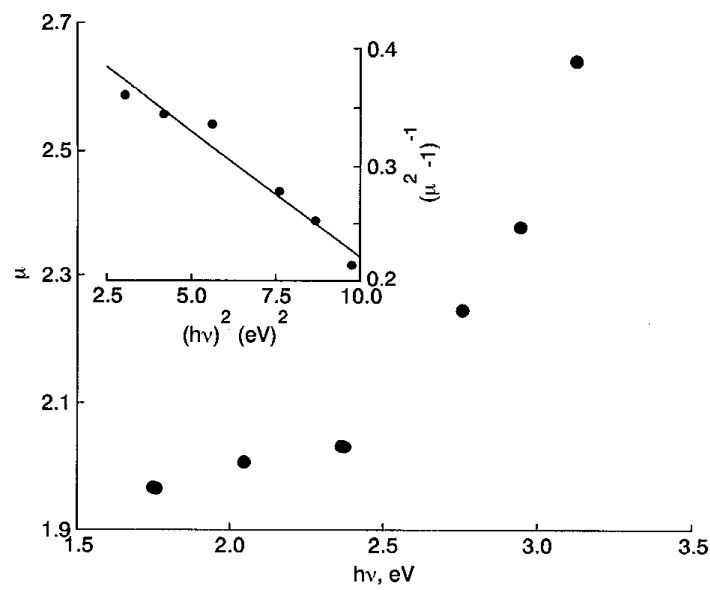

Fig. 4 Curve showing the variation of refractive index $\mu$ with incident photon energy hv for a seven layer thick $\mathrm{TiO}_{2}$ film

As shown in Fig. 4, refractive indices of a seven-layer thick $\mathrm{TiO}_{2}$ film are found to decrease with the wavelength.
This observation is consistent with results reported earlier [10]. Using the least-squares technique, a linear fit is obtained in the inset for the dependence of $\left(\mu^{2}-1\right)^{-1}$ on the square of photon energy $(h v)$. This implies that the dispersion relation can be explained in terms of the single oscillator model given in the form [16]

$$
\mu=\left[1+\frac{E_{d} E_{s}}{E_{s}-h^{2} \nu^{2}}\right]^{1 / 2}
$$

Values of the single effective oscillator energy $E_{d}$ and the dispersion energy $E_{s}$ are estimated to be $2.2 \mathrm{eV}$ and $16.5 \mathrm{eV}$ from the zero energy intercept and the slope of the graph, respectively. The average oscillator strength $S$ is estimated to be $23 \times 10^{12} \mathrm{~m}^{-2}$ from the relationship of $S=E_{d} E_{s} /\left(h^{2} c^{2}\right)$. Similar analysis was performed for the remaining layers and also for the samples prepared with the withdrawal speed of $100 \mathrm{~mm} / \mathrm{min}$. It is found that refractive indices show a weak dependence on the film thickness within the range considered.

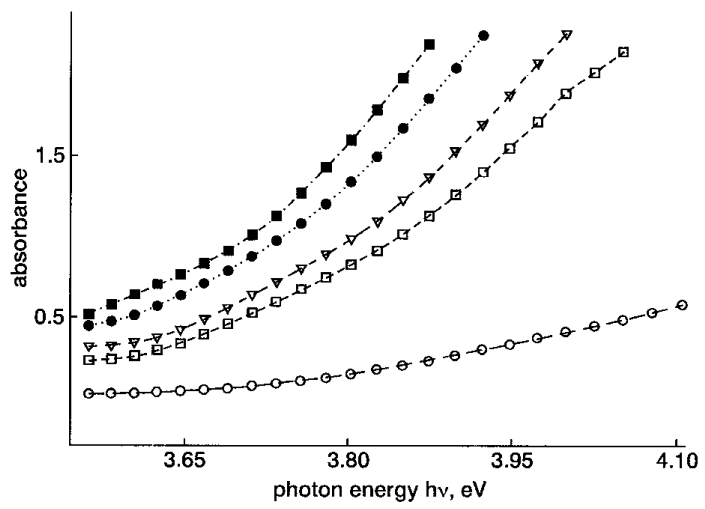

Fig.5 Absorption spectra for $\mathrm{TiO}_{2}$ film with five different thickness in the range of photon energy $3.5-4.1 \mathrm{eV}$

$0--0$ one layer

$\square-\square$ five layers

$\nabla--\nabla$ six layers

eight layers

Fig. 5 displays the absorbance as a function of incident photon energy $(h v)$ in the range $3.5-4.1 \mathrm{eV}$ for a variety of coating layers. Absorption edges are not expected to be sharp because of random orientation of crystallites within the region on which the incident beam is focused. It is to be noted that the absorption edge decreases to a lower energy for a multilayered sample than that for a single-layered film. The energy-dependence of the absorbance $A$ is usually written in the form [17]

$$
A(h \nu)=\left(\frac{B d}{h \nu}\right)\left(h \nu-E_{0}\right)^{n}
$$

where the optical band gap $E_{0}$ defines the energy position of the optical absorption edge and the power index $n$ describes the nature of electronic transitions. $B$ depends upon the minimum metallic conductivity $\sigma_{0}$, refractivc index $\mu$, the width of band edges $\Delta E$ and the nature of electronic transition $n$. Eqn. 6 is valid for the present investigation since the absorption coefficient is found to be greater than $10^{4} \mathrm{~m}^{-1}$ for all layers.

Eqn. 6 can be rewritten in the form [18]

$$
Y / Y^{\prime}=\frac{h \nu-E_{0}}{n}
$$

where $Y=A(h v) h v$ and

$$
Y^{\prime}=\frac{d[A(h \nu) h \nu]}{d(h \nu)}
$$


The midpoint difference rule is employed to compute the derivative $d[A(h v) h v] / d(h v)$ from the experimental data of Fig. 5. The advantage of using eqn. 7 is that there is no requirement of prior knowledge of the film thickness.

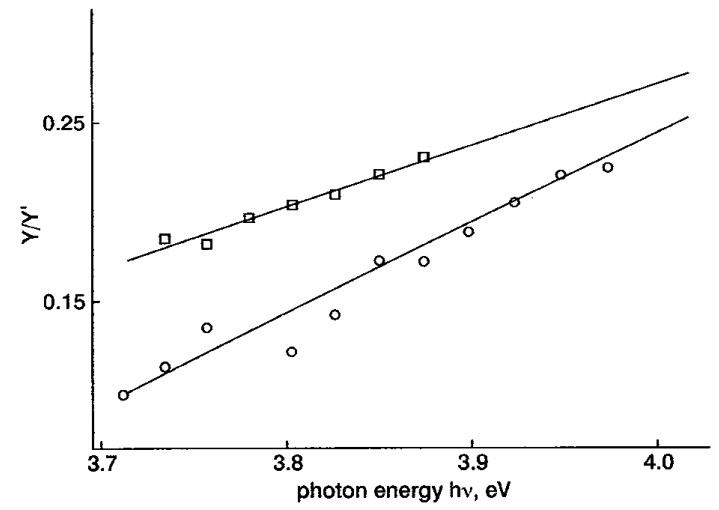

Fig.6 Two graphs showing linear dependence of $Y / Y^{\prime}$ on incident photon energy hv in the range of $3.7-4.0 \mathrm{eV}$ for an eight-layer thick $\mathrm{TiO}_{2} \mathrm{film}$ $\square$ eight layers

one layer

Fig. 6 shows the linear plots of $Y / Y^{\prime}$ as a function of $h v$ for photon energies greater than the absorption edge for one- and eight-layered thick films. Values of $n$ and $E_{0}$ are determined from the gradient and intercept, respectively. $E_{0}$ takes on values of $3.6 \mathrm{eV}$ and $3.3 \mathrm{eV}$ for single and eightlayered films, respectively. Similar analysis was performed for the remaining layers. It is found that the value of $E_{0}$ is independent of the number of coatings in a multilayered film and this observation agrees well with the plots in Fig. 5. The value of $n$ for a single layer is also different from that of multilayers. These data may be interpreted in terms of the model due to Mott and Davis [19] for nondirect transitions involving the energy supply by incident photons and no emission or absorption of phonons. The value of $n=2$ for a single layer implies that the probability of transitions between localised states is small. However, for $n=3$ in the case of a multilayered $\mathrm{TiO}_{2}$ film, transitions between localised states become equally probable in a multilayered system as those involving the continuum states. This is a feasible observation since the density of states localised at the interface between consecutive layers is large. In both cases, the density of states at the band edges is expected to be linear with energy, and the width of band edges may be derived from the relation [19]

$$
\Delta E=\left(\frac{4 \pi \sigma_{0}}{3 \mu c B}\right)^{1 / 2}
$$

where the velocity of light $c$ is taken to be $3.0 \times 10^{8} \mathrm{~ms}^{-1}$.

$\sigma_{0}$ is found to be $3.8 \times 10^{-4} \mathrm{Sm}^{-1}$ from the Arrhenius plot of conductivity of a $0.36 \mu \mathrm{m} \mathrm{TiO}_{2}$ film as a function of the inverse of temperature $T$ (Fig. 7). $B$ is assumed to be constant in the optical frequency range and $\Delta E$ is found to lie within the range of $0.1-0.2 \mathrm{eV}$. The electronic band gap $E_{C}$ $-E_{V}$ is, therefore, estimated to be $3.6 \mathrm{eV}$ for a multilayered film.

\section{Concluding remarks}

It is found that sol-gel derived $\mathrm{TiO}_{2}$ films possess a relatively high refractive index with its typical value of 2 at $500 \mathrm{~nm}$. Vorotilov et al. [20] determined an index of 2 for anatase, which is in agreement with the present data. The refractive index of $\mathrm{TiO}_{2}$ thin films prepared by ion beam assisted deposition methods lies between 2.3 and 2.7 [21].

304

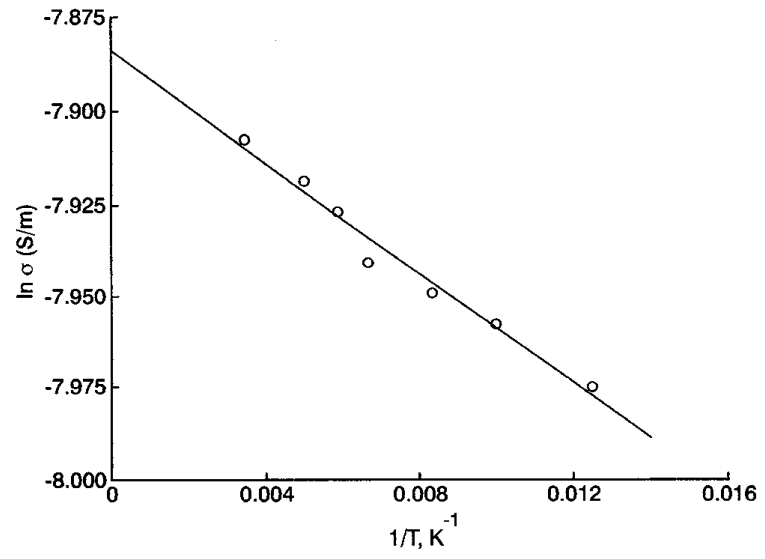

Fig.7 Variation of conductivity $\sigma$ with reciprocal temperature for $\mathrm{TiO}_{2}$ film

Values of the optical band gap $E_{0}$ are comparable to those previously reported for $\mathrm{TiO}_{2}$ films. Values of $E_{0}$ are found to be $3.2 \mathrm{eV}$ and $3.0 \mathrm{eV}$ for reactively triode sputtered $\mathrm{TiO}_{2}$ films in anatase and rutile, respectively [22]. Leinen et al. [23] have recently reported a band gap in the range of 3.3-3.42 eV for induced chemical vapour deposited anatase films. Fresnel loss occurs at the interface between the substrate and the first layer due to the mismatch in their refractive indices. It is also reported that sodium atoms diffuse into $\mathrm{TiO}_{2}$ film from the glass substrate [24]. This diffusion process is likely to cause the changes in optical properties of the single-layer film but no evidence of strong sodium contamination was, however, observed from the diffraction pattern for a single layer in the present studies. Both Fresnel and diffusion effects become less important for the subsequent coating of layers.

\section{Acknowledgments}

The authors are grateful to Dr A. Hassan of Sheffield Hallam University and Professor C.A. Hogarth of Brunel University for fruitful discussions. S.M. Tracey is grateful to Sheffield Hallam University for the award of a research studentship.

\section{References}

1 VANBOMMEL, , and BERNARDS, T.N.M.: 'Spin coating of titanium ethoxide solutions', J. Sol-Gel Sci. Technol., 1997, 8, (1-3), pp 459463

2 CANTAO, M.P., CISNEROS, J.L., and TORRESI, R.M.: 'Electrochromic behavior of sputtered titanium-oxide thin-films', Thin Solid Films., 1995,259 , pp. $70-74$

3 YOSHIDA, M., LAL, M., KUMAR, N.D., and PRASAD, P.N. ' $\mathrm{TiO}_{2}$ nano-particle-dispersed polyimide composite optical waveguide materials through reverse micelles', J. Mater. Sci., 1997, 32, (15), pp. 4047-4051

4 SOREK, Y., REISFELD, R., FINKELSTEIN, I., and RUSCHIN S.: 'Sol-gel glass waveguides prepared at low-temperature', Appl. Phys. Lett., 1993, 63, (24), pp. 3256-3258

5 WEINBERGER, B.R., and GARBER, R.B.: 'Titanium dioxide photocatalysts produced by reactive magnetron sputtering', Appl. Phys. Lett., 1995, 66, (18), pp. 2409-2411

6 HA, H., MOON, B.K., HORIUCHI, T., INSUSHIMA, T., ISHIWARA, H., and KONINUMA, H.: 'Structure and electric properties of $\mathrm{TiO}_{2}$ films prepared by cold plasma torch under atmospheric pressure', Mater. Sci. Technol., 1996, B41, pp. 143-147

7 LEE, W.G., WOO, S.I., KIM, J.C., CHOI, S.H., and OH, K.H. 'Preparation and properties of amorphous $\mathrm{TiO}_{2}$ thin films by plasma enhanced chemical vapour deposition', Thin Solid Films, 1994, 237, pp. 105-111

8 KIM, Y.J., and FRANCIS, L.F.: 'Processing and characterisation of porous $\mathrm{TiO}_{2}$ coatings', J. Am. Ceram. Soc., 1993, 76, (3), pp. 737-742

9 BACH, U., LUPO, D., COMTE, P., MOSER, J.E., WEISSOORTEL, F., SALBECK, J., SPREITZER, H., and GRATZEL, M. 'Solid-state dye-sensitized mesoporous $\mathrm{TiO}_{2}$ solar cells with high photon-to-electron conversion efficiencies', Nature, 1998, 395, pp. 583-585 
10 TRACEY, S.M., RAY, A.K., and SHISHIYANU, T.S.: 'Device characteristics of $\mathrm{CuPc} / \mathrm{TiO}_{2}$ heterojunctions', IEE Proc. Circuits Devices Syst., 1998, 145, (3), pp. 383-387

11 TRACEY, S.M., HODGSON, S.N.B., RAY, A.K., and GHASSEMLOOY, Z.: 'The role and interactions of the process parameters on the nature of alkoxide derived sol-gel films', J. Mater. Process. Technol. 1998, 7, pp. 86-94

12 SELVARAJ, U, PRASADARAO, AV KOMARNENI, S., and ROY, R.: 'Sol-gel fabrication of epitaxial and oriented thin films', $J$. Am. Ceram. Soc., 1992, 75, (5), pp. 1167-1170

13 O'REGAN, B., and GRATZEL, M.: 'A low-cost, high-efficiency solar cell based upon dye-sensitised colloidal $\mathrm{TiO}_{2}$ films', Nature, 1991 353, pp. $737-740$

14 KRUGER, J., BACH, U., and GRATZEL, M.: 'Modification of $\mathrm{TiO}_{\text {heterojunctions with benzoic acid derivatives in hybrid molecular }}$ solid-state devices', Adv. Mater., 2000, 12, (6), pp. 447-451

15 SWANEPOEL, R.: 'Determination of the thickness and optical-constants of amorphous-silicon', J. Phys. E, Sci. Instrum., 1983, 16, (12) pp. 1214-1222

16 WEMPLE, S.H., and DIDOMENICO, M: 'Behaviour of the electronic dielectric constant in covalent and ionic materials', Phys. Rev. 1971, 3, (4), pp. 1338-1351

17 TAUC, J.: 'The optical properties of solids' ABELES, F. (Ed.) (North-Holland Publ. Co. Amsterdam, 1970) p. 277
18 RAY, A.K., and HOGARTH, C.A.: 'On the analysis of experimental data on optical absorption in non-crystalline materials', J. Phys. D, Appl. Phys., 1990, 23, pp. 458-459

19 MOTT, N.F., and. DAVIS, E.A.: 'Electronic materials in non-crystalline materials' (Claredon Press, 1979) p. 291

20 VOROTILOV, KA ORLOVA, EV , and PETROVSKY, V.I.: 'Solgel TiO films on silicon substrates', Thin Solid Films, 1992, 207, pp. $180-184$

21 LEINEN, D., FERNANDEZ, A., ESPINOS, J.P., BELDERRAIN, T.R., and GONZALEZ-ELIPE, A.R.: 'Ion-beam-induced chemicalvapour-deposition for the preparation of thin-film oxides', Thin Solid Films, 1994, 241, (1-2), pp. 198-201

22 TANG, H., PRASAD, K SANJINES, R. SCHMID, P.E., and LEVY, F.: 'Electrical and optical properties of $\mathrm{TiO}_{2}$ anatase thin films', J. Appl. Phys., 1994, 75, (4), pp. 2042-2047

23 LEINEN, D., ESPINOS, J.P., FERNANDEZ, A., and GONZALEZ-ELIPE, A.R.: 'Ion-beam-induced chemical-vapor-deposition procedure for the preparation of oxide thin-films 1. Preparation and characterisation of $\mathrm{TiO}_{2}$ thin-films', J. Vac. Sci. Technol. A, 1994. 12, (5), pp. 2728-2732

24 FER NANDEZ A LASSALETTA G JIMENEZ VM JUSTO, A., GONZALEZ-ELIPE, A.R., HERRMANN, J.M., TAHIRI, H., and AITCHOU, Y.: 'Preparation and characterisation of $\mathrm{TiO}_{2}$ photocatalysts supported on various rigid supports (glass, quartz and stainless steel) Comparative studies of photocatalytic activity in water purification', Appl. Catalysis B - Environ., 1995, 7, (1-2), pp. 49-63 